theory of relativity or the quantum theory. ... I would definitely condemn any attempt to take such a question as that of the universal validity of the principle of the preservation of energy (questioned to-day in nuclear physics), and treat it as debatable, before pupils who cannot have properly grasped the meaning of the principle involved, still less its potential scope."

The principle has obviously other sound applica. tions than to latest theories in physics.

F. S. Marvin.

\title{
Interplanetary Travel
}

Rockets through Space:

or the Dawn of Interplanetary Travel. By P. E. Cleator. Pp. $246+22$ plates. (London: George Allen and Unwin, Ltd., 1936.) 7s. 6d. net.

$\mathrm{E}^{\mathrm{n}}$ VEN the man of science, devoted as he is to the open-minded examination of the facts of Nature as he finds them revealed by experiment, completely free as he should be of dogma and preconceived ideas when these do not agree with new facts, finds himself occasionally the target of abuse, accused of obscurantism, prejudice and an unwillingness to abandon orthodox ideas. On these occasions he should be meticulously careful to give the advocate of unorthodoxy a fair hearing, and in this spirit we approach Mr. Cleator's book, although the prospect of travelling through space to the other planets and returning safely again seems very remote.

It must be said at once that the whole procedure sketched in the present volume presents difficulties of so fundamental a nature that we are forced to dismiss the notion as essentially unpractical, in spite of the author's insistent appeals to put aside prejudice and to recollect the supposed impossibility of heavier-than-air flight before it was actually accomplished. An analogy such as this may be misleading, and we believe it to be so in this case. To begin with, the most powerful chemical reaction is unable to lift its own mass outside the earth's gravitational field: while the ejection of the burnt fuel decreases the load automatically, the comparative weakness of the fuel compels a mass ratio of fuel carried initially to working load which would deter all but the paper-bold, who do not flinch from the notion of a twenty million ton rocket required to project a twenty ton mass to Venus and back. We do not see how a small party of passengers, whose equipment is limited to ten tons, could hope to erect their return rocket, of mass two million tons, on the surface of an alien planet where they would be handicapped by an unnatural temperature and the necessity for wearing gas masks.

Mr. Cleator recognises the inadequacy of known fuels, and suggests the use of sub-atomic energy. If we ever discover how to release this safely, the position will indeed be changed, although in any event mass must be carried to generate momentum by ejection; but another suggestion, the annulment of gravity by electrical means, is without the experimental foundation which the author thinks it has. Then there are the difficulties connected with braking the descent on to a planet of the earth. There is no fuel to waste in braking by reverse rocket action; if there is no atmosphere, as on the moon, a parachute cannot work ; in the case of the earth, would any parachute stand the strain, and would not the whole con. trivance, rocket and parachute, burst into incandescence like a meteor? The incandescence might do no more than pit the surface of a thickwalled rocket, but must damage a light parachute structure.

Starting with the most open mind in the world, one must remain convinced that the time is not yet ripe for organising 'interplanetary societies' to discuss projects such as these. On the credit side, the societies have accomplished advances in the technique of rocket projection. One might suggest something that is possibly within their reach, and which would add materially to astrophysical knowledge. The spectrum of the sun in the far ultra. violet is inaccessible on earth on account of absorption in the atmosphere: it would appear possible to project a rocket to a height of a hundred miles above the earth's surface, carrying a spectrograph to secure the ultra-violet solar spectrum. A single exposure would decide whether the Lyman series is really so enormously strong as our present theories suppose it to be.

Returning to the 'sciences' of astronautics (a tolerable word) and astrogation (a terrible port. manteau word for astronautical-navigation), we are compelled to join the ranks of those whom Mr. Cleator stigmatises as visionless reactionaries, and to 'throw cold water' on the idea of interplanetary travel under present conditions. Let those who find themselves fascinated by this idea go quietly about the business of improving rocket design, rather than drum up publicity and complain of neglect. Mr. Cleator thinks it a pity that the Air Ministry evinced not the slightest interest in his ideas; provided that an equal indifference is shown by other Ministries elsewhere, we all ought to be profoundly thankful. $\quad$ R. v. d. R.W. 